\title{
Prominence of Direct Entorhinal-CA1 Pathway Activation in Sensorimotor and Cognitive Tasks Revealed by 2-DG Functional Mapping in Nonhuman Primate
}

\author{
Elżbieta Sybirska, Lila Davachi, and Patricia S. Goldman-Rakic \\ Yale University School of Medicine, Section of Neurobiology, New Haven, Connecticut 06510
}

The trisynaptic pathway from entorhinal cortex to the hippocampus has long been regarded as the major route of information transfer underlying memory consolidation. Most physiological studies of this pathway involve recording from hippocampal slices. We have used both single- and double-label 2-deoxyglucose autoradiographic methods to image the pattern of activation in the hippocampal formation of 14 rhesus monkeys performing cognitive tasks, varying in content (spatial or nonspatial), process (working memory or associative memory), and mode of response (oculomotor or manual). These studies revealed a highly differentiated pattern of metabolic activation throughout the rostrocaudal extent of the hippocampal formation that was common to all behavioral conditions examined. This pattern consisted of intense activation of the stratum lacunosummoleculare of CA1 and the subiculum, contrasting with barely detectable activity in CA3 and modest activation in the dentate gyrus, which did not include its molecular layer. These findings indicate a remarkable invariance in hippocampal activation under conditions of varied content, varied process, and varied mode of response and an heretofore-unappreciated preferential engagement of the direct rather than the trisynaptic pathway during performance of a wide range of behavioral tasks.

Key words: hippocampus; trisynaptic pathway; CA3; dentate gyrus; oculomotor delayed-response task; delayed match-tosample task; rhesus monkey
The hippocampal formation has been at the center of memory research since the early report of profound memory loss after extirpation of medial temporal structures in humans (Scoville and Miller, 1957). However, the exact nature of medial temporal lobe involvement in memory is currently undergoing reevaluation with evidence both for (Mishkin, 1978; Murray and Mishkin, 1984, 1986; Zola-Morgan and Squire, 1986; Zola-Morgan et al., 1989a; Murray et al., 1993; Alvarez et al., 1995) and against (Murray and Mishkin, 1998) a prominent influence of the hippocampus in recognition memory. In addition, a number of studies have demonstrated pronounced effects of perirhinal and parahippocampal cortex lesions on delay tasks in nonhuman primates (Zola-Morgan et al., 1989b,c; Gaffan and Murray, 1992; Meunier et al., 1993, 1996; Suzuki et al., 1993; Leonard et al., 1995; Murray et al., 1998). Information that may help determine the function of the hippocampus concerns its interactions with cortical areas. The polysynaptic (trisynaptic) circuit from the entorhinal cortex through the dentate gyrus and CA3 to CA1 has long been assumed, often tacitly, to be the major route by which cortically processed information is channeled into the hippocampus (Lomo, 1966; Bliss and Lomo, 1973; Malenka and Nicoll, 1999). On the other hand, recent electrophysiological and lesion experiments have called renewed attention to the importance of direct monosynaptic activation of CA1 by the entorhinal cortex (McNaughton et al., 1989; Yeckel and Berger, 1990; Jones, 1993; Buzsaki et al., 1995; Soltesz, 1995; Soltesz and Jones, 1995).

As part of a wider examination of the functional anatomy of memory systems in the nonhuman primate, the present study examined the functional contributions of the direct and indirect pathways to the hippocampal formation in monkeys trained on a

Received Dec. 6, 1999; revised April 17, 2000; accepted May 5, 2000.

This work was supported by National Institutes of Health Grants NMH 38546 and MH 00298. We thank Dr. Harriet Friedman for significant involvement in the early stages of this investigation and for consulting on the double-label method used in this study. We also thank Terri Beattie, Heather Findlay, and Mary Pappy for technical assistance.

Correspondence should be addressed to Dr. Patricia S. Goldman-Rakic, Section of Neurobiology, Yale University School of Medicine, 333 Cedar Street, New Haven, CT 06519. E-mail: patricia.goldman-rakic@yale.edu.

Copyright (C) 2000 Society for Neuroscience $0270-6474 / 00 / 205827-08 \$ 15.00 / 0$ broad variety of tasks. Very few methods allow functional appraisal of entire structures and their major subdivisions as they are engaged in the behaving organism. We applied the 2-DG metabolicmapping method to obtain maps of brain activity in monkeys performing tasks with different mnemonic demands. The excellent spatial resolution of this method (Sokoloff et al., 1977; Friedman et al., 1989) and its preferential labeling of activated terminal fields (Sokoloff, 1993a,b) allowed us to differentiate the functional involvement of the two major inputs to the hippocampus.

Two types of tasks were used in our experiments: a manual object recognition memory task [delayed match-to-sample (DMS) task] and several oculomotor delayed-response (ODR) tasks. The DMS task is commonly used to assess the effects of hippocampal lesions in nonhuman primates, whereas ODR tasks are widely used to reveal the task-related responses of individual neurons engaged by working-memory demands (Funahashi et al., 1989; Chafee and Goldman-Rakic, 1998). We reasoned that the ODR tasks, in which the stimuli, the mnemonic requirements, and the motor responses of the monkeys were precisely controlled, would optimize the search for neural specificity in the coding of qualitatively different memoranda by the hippocampus. Furthermore, a double-label 2-DG method was used in the majority of monkeys to detect patterns of activity associated with two different tasks performed by the same animal sequentially. This was done to eliminate individual differences as a cause of possible task differences, while also doubling the amount of information per animal (Friedman et al., 1987, 1989). Our hypothesis was that a structure engaged in encoding might exhibit differential activation dependent on the nature of the memoranda (spatial or nonspatial), the nature of processing (e.g., working vs associational memory; memory guided vs sensory guided), and/or the mode of response (manual vs oculomotor)—all of which were compared in the present study.

\section{MATERIALS AND METHODS}

Subjects

Fourteen male rhesus monkeys, 3-5 years of age, were used in this study. The animals were housed in separate cages and fed a diet consisting of monkey chow supplemented with fruit. When being tested, monkeys were either restricted to $200 \mathrm{ml}$ of water per day except on weekends (eight 


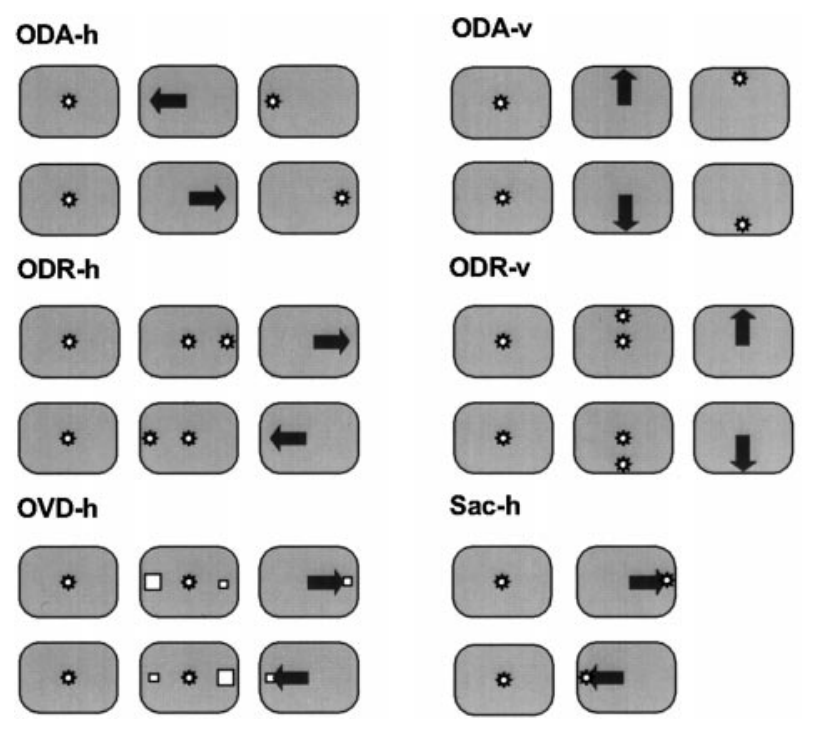

Figure 1. Schematic of six oculomotor tasks used in double-label 2-DG experiments. Asterisks indicate fixation and the target diodes, arrows indicate response directions, and white squares represent stimuli used in the visual discrimination task. $O D A-h$, Delayed alternation-horizontal targets; $O D A-v$, delayed alternation-vertical targets; $O D R-h$, delayed responsehorizontal targets; $O D R-v$, delayed response-vertical targets; $O V D-h$, visual discrimination-horizontal targets; $S a c-h$, saccades-horizontal targets. See text for further description.

monkeys performing ODR tasks) or food deprived [six monkeys tested in the Wisconsin General Test Apparatus (WGTA)].

\section{ODR tasks}

ODR tasks were conducted as double-label experiments, and hence each of eight monkeys performed two ODR tasks in sequence. Each monkey was trained to sit quietly in a primate chair with its head fixed. The monkeys were trained to fixate a central diode and move their eyes to various peripheral locations, 13 or $15^{\circ}$ to the left/right or above/below the fixation point. Eye movements were recorded with a scleral eye coil (CNC Engineering, Seattle, WA). Altogether, hippocampal metabolism was examined under the different conditions illustrated in Figure 1: delayed alternation for horizontal targets $(n=4)$, delayed alternation for vertical targets $(n=2)$, spatial delayed response $(n=4)$, delayed visual discrimination $(n=2)$, and a sensory-guided spatial saccade task $(n=4)$. All animals were trained to a criterion of $85-90 \%$ correct trials on their respective tasks for at least 5 consecutive days before the 2-DG experiment was performed. A detailed description of these tasks is presented below.

Saccade task. The monkey was required to fixate the central diode for a variable $1-2 \mathrm{sec}$. At the end of this period, a diode was illuminated to the left or to the right of the horizontal meridian or above or below the vertical meridian, and the monkey simply had to direct its gaze to that stimulus.

ODR task. As the monkey fixated the central diode, one of the peripheral diodes was illuminated for $0.2 \mathrm{sec}$ according to a quasi-random sequence. After a variable delay of 1.5-3.0 sec, the central diode was turned off, signaling the monkey to direct its gaze to the location of the previously displayed peripheral cue.

Oculomotor delayed-alternation tasks. The oculomotor delayedalternation (ODA) tasks required the monkey to remember the direction of its last response to make a current response in the opposite direction, e.g., left, right, left, right, left, right. After a random period $(1.5-3.0 \mathrm{sec})$ of fixation, the central diode was switched off, releasing the monkey to make an eye movement to one of the two peripheral targets. A diode was illuminated after a response to the correct location to inform the animal that its response was correct. On the following trial the required response was to direct the eyes to the target at the opposite location. Thus, in the ODA-horizontal task (ODA-h), monkeys alternated eye movements to the left or to the right of fixation, whereas in the ODA-vertical task (ODA-v), they alternately directed eye movements to positions above and below the central diode.

Visual discrimination task. In the visual discrimination task (OVD), two different-sized squares $\left(1\right.$ and $\left.4^{\circ}\right)$ appeared simultaneously at the right and left $13^{\circ}$ locations for $0.5 \mathrm{sec}$ during fixation on the central diode. After a delay of $1.5 \mathrm{sec}$, the central diode was turned off, and the animal was required to move its eyes to the position in which the small square had been presented.

\section{Manual tasks}

Hippocampal metabolism was also examined during manual behavioral tasks conducted in a WGTA under two memory conditions: manual de- layed spatial alternation (MDA) $(n=3)$ and DMS $(n=3)$. Performance in these tasks is assessed under more natural conditions in which the animal is seated in a primate chair with its head free and it responds by displacing plaques or objects manually. Three monkeys that were subjects in our previous reports (Friedman and Goldman-Rakic, 1988; Davachi et al., 1995) provided single-label data for the MDA task, and three additional monkeys were trained to perform a DMS task.

Manual MDA. On the first trial with the screen lowered between the animal's compartment and the test tray, both wells were baited and covered with identical cards. As in the ODR task, either response made on the first trial was rewarded. On the next and all subsequent trials, the monkey was rewarded for selecting the well not chosen on the previous trial.

Manual DMS. On each trial, a unique three-dimensional object was presented in the center of the test tray. The animal was required to touch and move the sample to retrieve a hidden reward. The screen was then lowered for a fixed delay $(12 \mathrm{sec})$, after which the screen was raised and the sample and a new object were presented for choice. The animal was rewarded for selecting the object that had been used as a sample.

\section{2-DG protocol for double-label experiments}

The 2-DG ([ $\left.{ }^{14} \mathrm{C}\right] 2-\mathrm{DG}, 57.2 \mathrm{mCi} / \mathrm{mmol}$; $\left[{ }^{3} \mathrm{H}\right] 2-\mathrm{DG}, 26 \mathrm{Ci} / \mathrm{mmol}$; New England Nuclear Life Sciences) was obtained in saline solution. A 200/1 ratio was achieved by administering $50 \mathrm{mCi} / \mathrm{kg}\left[{ }^{14} \mathrm{C}\right] 2-\mathrm{DG}$ and $250 \mu \mathrm{Ci} / \mathrm{kg}$ $\left[{ }^{3} \mathrm{H}\right] 2-\mathrm{DG}$. In the double-label protocol, seven monkeys received $\left[{ }^{3} \mathrm{H}\right] 2$ DG first and $\left[{ }^{14} \mathrm{C}\right] 2-\mathrm{DG}$ second. In three monkeys the order of isotope injection was reversed. The first injection of 2-DG, regardless of radiolabel, was followed by $30-35$ min of behavioral testing, and the second injection was followed by $10-15$ min of testing. These temporal parameters have been used previously to demonstrate ocular dominance columns in the visual cortex of rhesus monkeys (Friedman et al., 1989).

\section{2-DG protocol for single-label experiments}

The quantitative 2-DG method developed by Kennedy et al. (1978) was followed. All animals received arterial and venous catheters before the 2-DG experiment under gas anesthesia. After full recovery from this procedure $(\sim 2 \mathrm{hr}$ after the monkey regained consciousness), the testing session began. The animals were injected with $\left[{ }^{14} \mathrm{C}\right] 2-\mathrm{DG}(100 \mu \mathrm{Ci} / \mathrm{kg}$ in $1 \mu \mathrm{Ci} / 10 \mu \mathrm{l}$ of sterile saline) followed by a saline flush. Timed arterial blood samples were taken over the 45 min experiment.

\section{Perfusion, histology, and autoradiography}

At the conclusion of the 45 min testing session, the monkeys were given an intravenous lethal dose of sodium pentobarbital and a warm $\left(37^{\circ} \mathrm{C}\right)$ saline flush and immediately perfused intracardially with a cold $\left(6^{\circ} \mathrm{C}\right) 3.3 \%$ paraformaldehyde solution in phosphate buffer, $\mathrm{pH}$ 7.4. The brain was removed usually within $15 \mathrm{~min}$. Hemispheres were separated, and each was cut into several blocks. Each block was quickly frozen in methylbutane at $-50^{\circ} \mathrm{C}$ and stored at $-70^{\circ} \mathrm{C}$. Brain tissue sections were cut $20 \mu \mathrm{m}$ thick at $-20^{\circ} \mathrm{C}$ on a cryostat (Hacker, Fairfield, NJ). Sections for autoradiograms were collected in different intervals ranging from 60 to $400 \mu \mathrm{m}$. The sections were mounted on cold coverslips and rapidly dried on a hot plate $\left(50^{\circ} \mathrm{C}\right)$ and then taped to cardboard for exposure to film in $\mathrm{x}$-ray cassettes. For the double-label experiments, brain sections together with plastic ${ }^{14} \mathrm{C}$ and ${ }^{3} \mathrm{H}$ standards (Amersham, Arlington Heights, IL) were first opposed to SB-5 (Eastman Kodak, Rochester, NY) and subsequently to Hyperfilm (LKB-Wallac, Gaithersburg, MD) to generate two sets of film. In singlelabel experiments, sections were opposed only to x-ray film (SB-5 or Biomax; Eastman Kodak). To define anatomical structures, sections taken at $200 \mu \mathrm{m}$ intervals were mounted on slides and counterstained with cresyl violet.

\section{Double-label autoradiograms}

As described previously (Friedman et al., 1987), brain sections were opposed to SB-5 films covered with thin $(127 \mu \mathrm{m})$ plastic sheets (Mylar) to generate films composed of radioactivity patterns associated only with the uptake of $\left[{ }^{14} \mathrm{C}\right] 2-\mathrm{DG}$. In addition, the same sections were subsequently opposed to Ultrafilm, which is not isotope specific, to reveal the composite pattern of 2-DG uptake for ${ }^{14} \mathrm{C}$ and ${ }^{3} \mathrm{H}$. To obtain the pattern of 2-DG activity associated with ${ }^{3} \mathrm{H}$ only, we used the subtraction algorithm described by Friedman et al. (1987). Briefly, x-ray/Mylar and Ultrafilm autoradiograms of identical brain sections were digitized and aligned, and the raw values were translated to radioactivity values based on the ${ }^{14} \mathrm{C}$ standards. In the next step the contaminated ${ }^{14} \mathrm{C}$ values on Ultrafilm were subtracted using values from $x$-ray film. The resulting image represents the activity component attributable to ${ }^{3} \mathrm{H}$.

\section{Single-label autoradiograms}

Autoradiograms obtained from brain sections were standardized and curve-fitted according to the Sokoloff model of 2-DG uptake (Kennedy et al., 1978). Autoradiograms of brain sections were digitized using an imageprocessing system comprised of a PDP-11 computer and video camera described previously (Friedman et al., 1987, 1989) and a microcomputer imaging-device (Imaging Research, St. Catharines, Ontario, Canada). The ${ }^{14} \mathrm{C}$ standards opposed to the film together with brain sections were digitized and used as the reference for calibrating radioactivity in the 

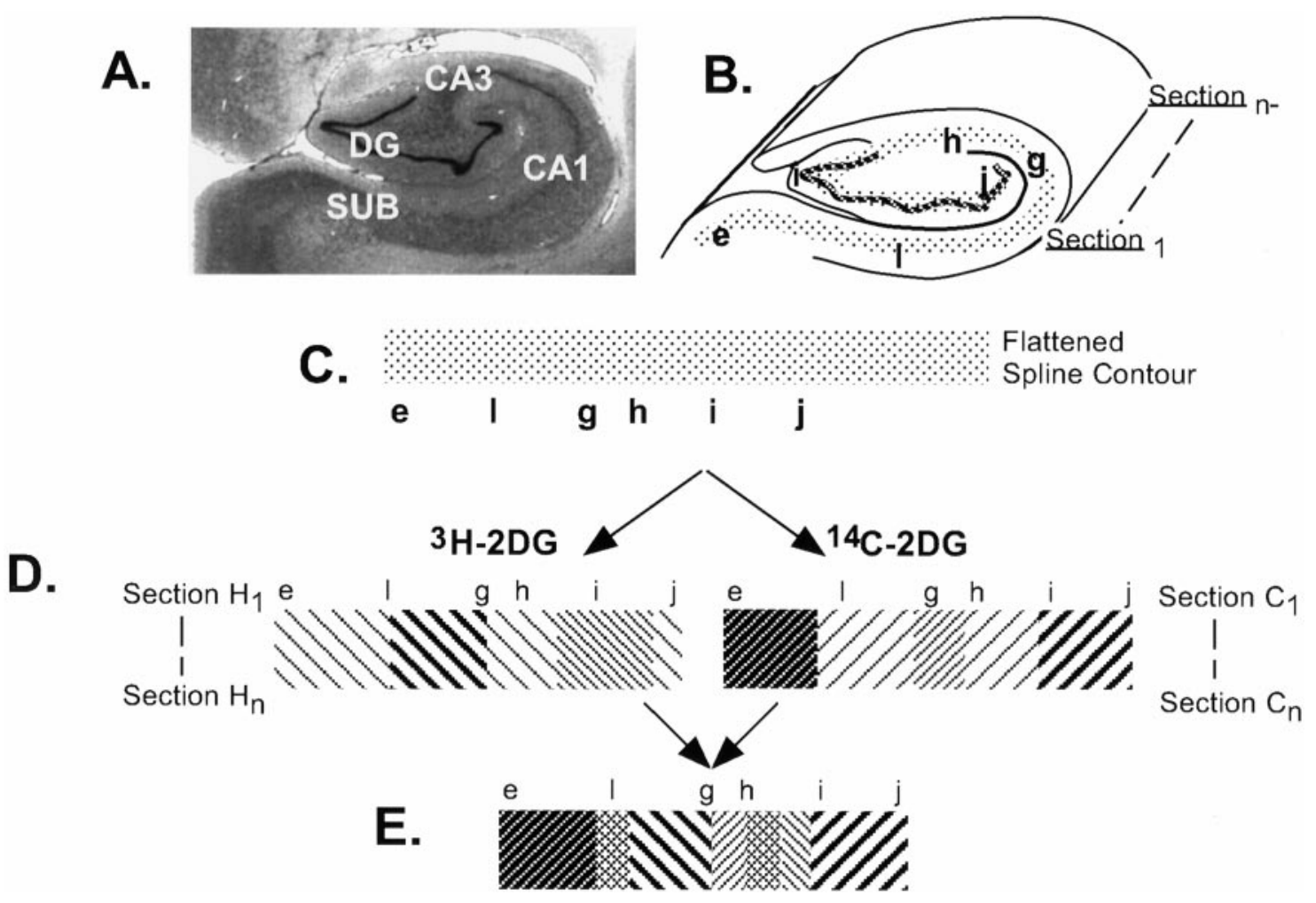

Figure 2. Schematic illustration of analysis of double-label autoradiograms. A, Anatomical borders of the hippocampus were identified from cresyl violet-stained sections. $B$, Hippocampal layers were outlined by a series of points, which were connected to produce a spline (gray band). $C$, The spline contour was flattened. $D$, In double-label experiments, identical splines were applied to pixel-by-pixel-aligned ${ }^{3} \mathrm{H}$ and ${ }^{14} \mathrm{C}$ images. Activity measured within the width of the spline was averaged and presented as flattened strips of activity. Stacking these pseudocolor strips rostrocaudally allowed us to produce two-dimensional maps of radioactivity across the rostrocaudal extent of the hippocampus including the dentate gyrus, CA3, CA1, and subiculum subfields. $E$, Superimposing each activity map from the same brain allowed us to visualize different or overlapping metabolic activations in two different behavioral conditions. $D G$, Dentate gyrus; $S U B$, subiculum.

brain. The gray values of each pixel of digitized brain section were converted to ${ }^{14} \mathrm{C}$ tissue concentration equivalents by linear interpolation.

\section{Analysis of 2-DG activity: flat maps}

After identifying anatomical borders of structures from cresyl violetstained sections, we transferred them to the autoradiographic images. Hippocampal layers were outlined by a series of points, which were connected using the B-spline algorithm of Newman and Sproull (1973). In double-label experiments, identical splines were applied pixel by pixel to aligned ${ }^{3} \mathrm{H}$ and ${ }^{14} \mathrm{C}$ images. Measured activity within the width of the spline was averaged. The profile of the activity was presented in two forms, as a histogram for each pixel of the spline or as a flattened pseudocolor strip of activity. Stacking these pseudocolor strips rostrocaudally allowed us to produce two-dimensional maps of radioactivity in subicular subfields, CA1, CA3, and the dentate gyrus across most of the rostrocaudal extent of the hippocampus formation (Fig. 2).

\section{Analysis of the local maxima of 2-DG activation}

Statistical criteria were used to identify mean activation in the selected region of interest. The mean activity was determined for each individual section. All pixels, which were at least 1.5 SDs above the mean value, were highlighted. For visual optimization of the image, a size filter was applied to activations of a single pixel.

\section{RESULTS}

As will be described below, the major finding from this study is a remarkably consistent pattern of activation across all tasks, whether oculomotor or manual, whether spatial or nonspatial, whether memory guided or sensory guided. The dominant pattern of hippocampal activation is consistent with engagement of the direct pathway, with much less involvement of the trisynaptic pathway. The results for each task will be presented below.

\section{Double-label experiments}

\section{$O D A-h$}

Three monkeys performed ODA-h as the first task, and one animal performed it as the second task. The pattern of metabolic activa- tion of the hippocampal formation in a monkey performing ODA-h is shown in Figure $3 A$. High metabolic activation was present in the subiculum, in CA1, and in the dentate gyrus, contrasting with very little activation in CA3. The highest activation was always present in CA1, and activation was more moderate in the subiculum and dentate gyrus. Within CA1, the entire stratum lacunosum-moleculare was activated uniformly, unlike the stratum radiatum-pyramidale where activation was strong only at their borders with the subiculum and CA3 and was low between these borders. In the subiculum, metabolic activation was present in all layers, although higher in deeper layers then in the molecular layer. In the dentate gyrus, activation was mainly confined to the granule cell layer. As illustrated in two-dimensional maps, this distinctive pattern was visible throughout the entire hippocampal formation, forming rostral-caudal stripes of activation in CA1 and the subiculum, interspersed with a darker stripe representing barely detectable activity in CA3 (Fig. 4). The same pattern of activation was observed in all monkeys performing this task independent of task order.

$O D A-v$

One of two monkeys performed ODA-v first, and the other performed it second. The mnemonic requirements of the ODA-v task are identical to those in ODA-h except for the direction of response. Again, as in $\mathrm{ODA}-\mathrm{h}$, the most striking activation was observed in the subiculum and CA1 fields, in the latter throughout the entire stratum lacunosum-moleculare (Fig. $3 B$ ). This activation extended into the stratum radiatum-pyramidale of the CA1 at the borders with adjacent subfields. As in ODA-h, activation in the subiculum was present in all layers. Activity in the dentate gyrus was confined to the granule cell layer and was conspicuously low or absent in the entire CA3 subfield. Two-dimensional reconstructions of the stratum radiatum-pyramidale and stratum lacunosum- 


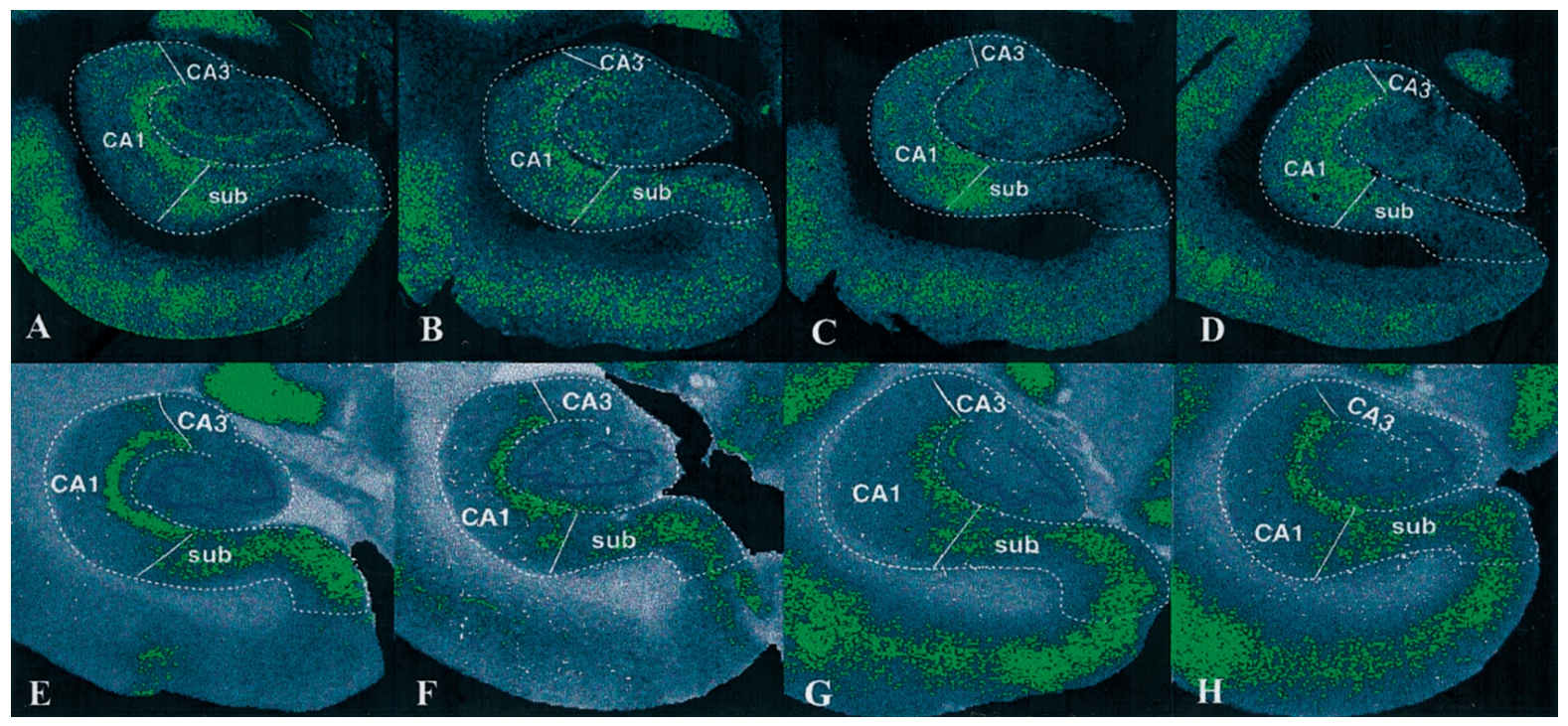

Figure 3. Examples of the local maxima of 2-DG activation in coronal sections through the hippocampal formation of eight monkeys illustrating the similarity of activation profiles (notably the high metabolic activity in the subiculum and CA1 molecular layer and the low activity in CA3) during the performance of the different oculomotor $(A-D)$ and manual $(E-H)$ tasks. Dashed white lines outline the sampled region from which average radioactivity was obtained. Green indicates pixels reaching an activation threshold set 1.5 SDs above the mean activity for the sampled area. For clarity, single pixels are removed. Solid white lines indicate borders between hippocampal subfields: between the subiculum (sub) and CA1 and between CA1 and CA3. $A$, ODA-h task. $B$, ODA-v task. $C$, ODR-h task. $D$, Sac-h task. $E-G$, Metabolic activation in three monkeys performing the MDA task. $H$, DMS task.

\section{ODA-h}

pyr
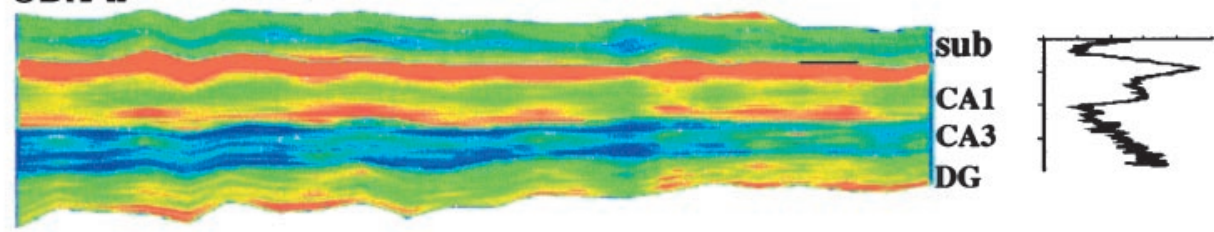

mol
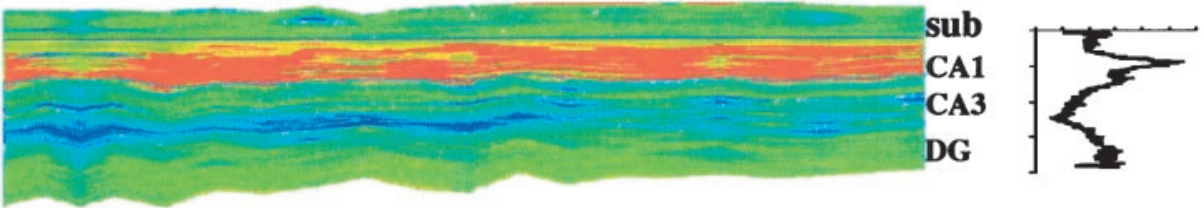

Figure 4. Two-dimensional (flattened) maps illustrating the stripe-like pattern of metabolic activity through the entire hippocampal formation, forming rostralcaudal stripes of high activation (red) interspersed with stripes representing barely detectable activity (blue). The rostral hippocampus is on the left; caudal is on the right of each map. Activity in the stratum lacunosum-moleculare $(\mathrm{mol})$ and in the pyramidal layer ( $p y r)$ of the hippocampal formation are presented separately for monkeys performing the ODA-h, ODA-v, and Sac-h tasks, as indicated. The hippocampal subfields are labeled the subiculum (sub), CA1, CA3 and the dentate gyrus $(D G)$. Histograms (top right) representing the average activity over several millimeters of the hippocampal formation are presented for the ODA-h task.

\section{ODA-v}

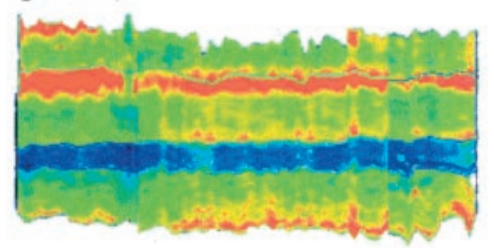

mol

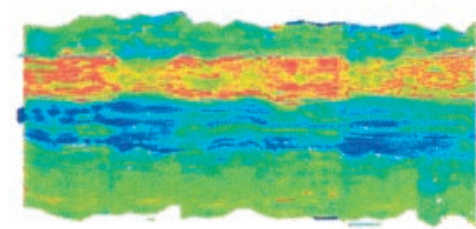

SAC-h
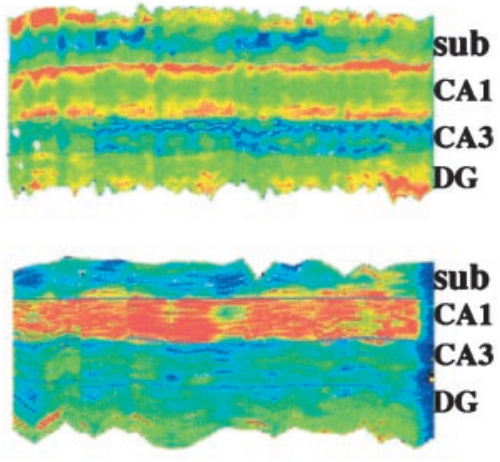

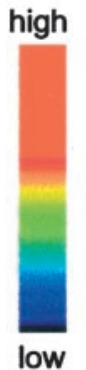

moleculare of the hippocampal formation in the ODA-V condition revealed distinct stripes of high metabolic activation in the subiculum, in CA1, and in the dentate gyrus (Fig. 4). The activation in the subiculum and stratum lacunosum-moleculare of CA1 was homogeneous. Dentate gurus activation was confined to the granule cell layer. Again, little or no metabolic activity was visible in CA3, as evidenced by a blue band.

$O D R-h$

Two monkeys performed this task, each with a different isotope order. An example of activation in the coronal section from one of these monkeys is presented in Figure 3C. Again the subiculum, $\mathrm{CA} 1$, and the dentate gyrus all displayed high activation relative to that in CA3. In this case the subicular complex was uniformly activated. As in the previously described cases, activation in CA1 was highest in the stratum lacunosum-moleculare and appeared bimodal in the stratum pyramidale radiatum-pyramidale, i.e., evident as peaks of activity at the border zones. Metabolic activation visualized throughout the rostrocaudal extent of the hippocampal formation formed three stripes of activity representing the subicular complex, CA1, and the dentate gyrus granule cell layer. The CA3 subfield was represented by a stripe of low activation, whereas 


\section{MDA DMS}

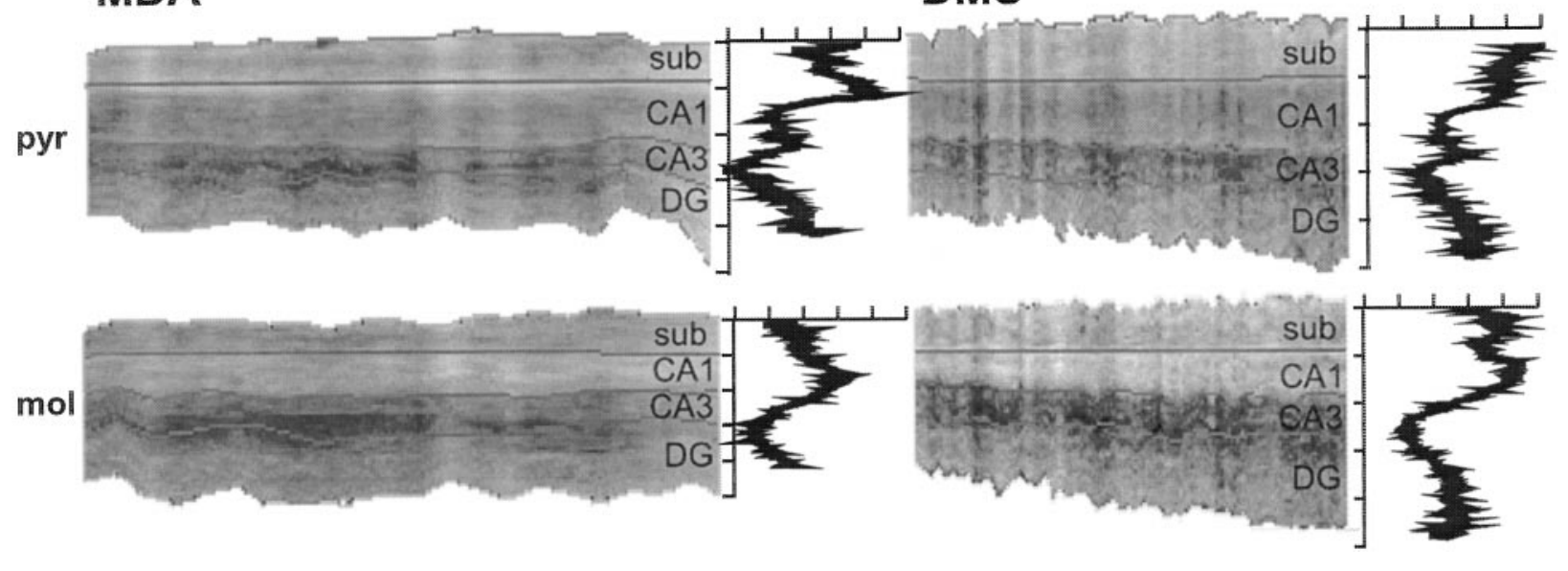

Figure 5. Two-dimensional maps illustrating the stripe-like pattern of metabolic activity through the rostrocaudal extent of the hippocampal formation in two monkeys performing manual tasks. Rostral to caudal runs from left to right in these maps. Top, Activation in the pyramidal layer ( $p y r$ ) during MDA (left) and DMS (right) performance. Bottom, Activity in the molecular layer ( $\mathrm{mol}$ ) during MDA (left) and DMS (right) performance. Histograms for averaged activity are presented to the right of each map. $D G$, Dentate gyrus; sub, subiculum.

the most intense metabolic activation was present in the molecular layer of CA1 (data not shown).

\section{Saccade task-horizontal targets}

Two monkeys performed this task, both as a second task. Again, the pattern of metabolic activation consisted of high activity in the subiculum, CA1, and the dentate gyrus and barely detectable activation of CA3. Activation in CA1 was more diff use than that in other tasks (Figs. 3D, 4).

\section{OVD-h}

Two monkeys performed this task as their second test. This task requires the animal to remember the position of the small square. The metabolic activation in the hippocampal formation in these animals displays a pattern very similar to that described in all previous tasks - high metabolic activation in the subicular complex, the CA1, and the dentate gyrus and very low activity in CA3. The CA1 activation was present in all layers but was especially high and uniform in the stratum lacunosum-moleculare. The same pattern was observed throughout the reconstructed portion of the hippocampal formation (data not shown).

\section{Single-label experiments \\ MDA manual task}

The activity in the hippocampal formation of three monkeys that performed MDA displayed high metabolic activation in the subiculum, CA1, and the dentate gyrus (see Fig. $3 E-G$ ). Again, as in the ODR monkeys, the stratum lacunosum-moleculare of CA1 was essentially uniformly activated, whereas the stratum radiatum and pyramidale showed peaks of activity at the CA1 borders with the subiculum and CA3. The subiculum showed activity in all layers. Activity in the dentate gyrus was confined to the granule cell layer. The flat maps of metabolic activation showed high metabolic activity through the stratum radiatum-pyramidale and stratum lacunosum-moleculare of CA1 along the rostrocaudal extent of the hippocampal formation in all three monkeys that performed this task (Fig. 5).

\section{DMS manual task}

The three monkeys that performed this task exhibited high metabolic activity in the subiculum, CA1, and the dentate gyrus. Again, similar to the ODR monkeys, the stratum lacunosum-moleculare of CA1 was uniformly highly activated, whereas activation in the stratum radiatum-pyramidale of CA1 was moderate with peaks of high activity at the borders with the subiculum and CA3 (Fig. $3 H$ ). Metabolic activation in the subiculum was as in other behavioral conditions. The activity in the dentate gyrus was more prominent in these monkeys and was present not only in the granule cell layer but also to some extent in the molecular layer. CA3 however expresses very little activity in all layers (Fig. 5).

\section{DISCUSSION}

The major finding of the present study is the common pattern of metabolic activation in the hippocampal formation during performance of a wide variety of behavioral tasks, including oculomotor and manual working-memory tasks. This pattern consisted of elevated activity in the granule cell layer of the dentate gyrus and in all layers of the CA1 and subiculum whereas activity in the molecular layer of the dentate gyrus and in CA3 was barely detectable. Although all layers of CA1 displayed high metabolic activation, the highest and most uniform activation was present as a wide band in the stratum lacunosum-moleculare and bimodal activation in the stratum radiatum and pyramidale with peaks of activity at the border zones. Two-dimensional reconstructions of the hippocampal formation revealed a uniform pattern of activation throughout a considerable rostrocaudal expanse of hippocampus. Flattened maps of the hippocampus revealed a striking stripe-like pattern of activation, which represented the summed activity in a minimum period of $10 \mathrm{~min}$. To our knowledge this is the first in vivo visualization of hippocampal subfield activation over a relatively brief unit of time, commensurate with the time course of synaptic phenomena such as long-term potentiation (Malenka and Nicoll, 1999).

\section{Direct versus trisynaptic pathway}

The trisynaptic pathway has long been assumed to be the critical circuit for encoding and consolidating information in long-term memory and the major throughput to other structures. The trisynaptic pathway originates from layer II of the entorhinal cortex and synapses on the outer two-thirds of granule cell dendrites in the dentate gyrus that, in turn, give rise to the mossy fiber projection to CA3 pyramidal cells and from them to pyramidal cells in CA1 via Schaffer collaterals (Lorente de No, 1934; Ramon y Cajal, 1968; Steward, 1976; Amaral and Witter, 1989; Lopes da Silva et al., 1990). Because terminal projection zones of activated pathways are revealed by the 2-DG method (Sokoloff, 1993a,b) and on the basis of the anatomical considerations, tasks that engage the trisynaptic pathway should activate the molecular layer of the dentate gyrus and the pyramidal cell layers of CA3 and CA1. The present findings, however, suggest a selective involvement of the direct monosynaptic pathway from EC to CA1 during the performance of a multitude of tasks, most of which require updating of information 
on a trial-by-trial basis. The prominence of this pathway in our study is consistent with a long line of anatomical, physiological, and behavioral observations. As early as 1934, Lorente de No (1934) described direct connections from the entorhinal cortex to the pyramidal cells of CA1, and this direct pathway was confirmed by subsequent tracing studies (Witter et al., 1988, 1989; Amaral and Witter, 1989). Furthermore, electrical stimulation of entorhinal afferents produces short-latency potentials in CA1 pyramidal cells (Spencer and Kandel, 1962; Segal and Olds, 1972; Fox and Ranck, 1981; Doller and Weight, 1982; Yeckel and Berger, 1990; Soltesz and Deschenes, 1993). Furthermore, monosynaptic responses evoked by low-frequency perforant pathway stimulation are relatively stronger than are disynaptic and trisynaptic responses elicited via the trisynaptic loop (Yeckel and Berger, 1990, 1995). Metabolic experiments in rodents have also suggested that monosynaptic connections to the hippocampus are functionally important (Jorgensen and Wright, 1988). The functional significance of direct connections to CA1 is also suggested by the persistence of spatial selectivity in "place" cells of CA1 in a radial maze after massive destruction of granule cells in the dentate gyrus (McNaughton et al., 1989). A possible caveat to this hypothesis is suggested by the observation that the molecular layer of the subiculum was not as strongly activated as its deeper layers yet is the layer that receives entorhinal input. On the other hand, this observation may indicate a preferential functional connection from the entorhinal cortex to CA1 with respect to the present behavioral conditions. That CA1 afferents terminate in deeper layers of the subiculum (Amaral et al., 1991; Witter, 1993) is additional support for this interpretation. Why the CA1 component of the direct pathway should be functionally prominent is unclear, and it will remain for future studies to examine the possible basis of differential involvement of each component (e.g., CA3, subiculum) in sensorimotor and cognitive performance.

Recently, several new human cases with lesions in the hippocampal formation arising from acute disease or cardiovascular events have been added to the literature (Zola-Morgan et al., 1986; Rempel-Clower et al., 1996; Reed and Squire, 1997, 1998; Kapur and Brooks, 1999). Bilateral damage confined to the CA1 region of the hippocampal formation is sufficient to produce moderately severe anterograde memory impairment and extensive, temporally graded retrograde amnesia (Zola-Morgan et al., 1986; Kartsounis et al., 1995; Rempel-Clower et al., 1996). These neuropsychological findings would be predicted if the direct pathway were an obligatory component of the normal functions of the hippocampus.

\section{Diverse behavioral tasks: common activation}

In the present study, metabolic activation was analyzed in animals performing both conventional delayed-response tasks in a WGTA and in ODR paradigms. In spite of the differences between tasks, no fundamental difference in the pattern of metabolic activation was observed. It should be emphasized, however, that a common pattern of activity in no way precludes the existence of quantitative differences between the various behavioral conditions. Indeed, our previous study revealed quantitative differences between workingmemory and associative-memory tasks (Friedman and GoldmanRakic, 1988). The present findings emphasize the fact that the CA1 subfield is highly responsive to performance on a wide variety of cognitive tasks and add the subiculum to the list of structures that may contribute to performance of such tasks.

The resolution of the 2-DG method used in the present study is one of the highest achievable with current imaging methods and should be sufficient to reveal task-dependent foci within the hippocampal subfields. In fact, we were able to differentiate activation between the stratum lacunosum-moleculare and stratum radiatumpyramidale of CA1. Furthermore, our double-label 2-DG method should be sensitive to task differences, if there were any, because each animal serves as it own control for all comparisons. Finally, by reconstructing activity throughout virtually the entire rostrocaudal extent of the hippocampal formation, we expected to detect re- gional variations, interdigitation, or focal activation across task conditions. No such task-related variations were detected.

As far as we are aware, the present study is the first to examine hippocampal activation in the ODR task. The ODR tasks were chosen in this study for two reasons: to control animal behavior and to test direction-specific coding of hippocampal neurons in spatial processing (O'Keefe, 1976, 1993; Olton and Papas, 1979; McNaughton et al., 1983; Miyashita et al., 1989; Nishijo et al., 1997; Rolls et al., 1997, 1998). Little evidence was found for topographic representation of information within the hippocampal formation. However, we have demonstrated that constrained oculomotor tasks engage the hippocampal formation in the same way as do manual tasks conducted in a WGTA. All approaches we used consistently expressed a pattern of metabolic activation implicating the direct monosynaptic pathway.

The failure to dissociate activity patterns for spatial and nonspatial tasks indicates that the direct pathway, at least, is not selective for one or the other processing domain. Our finding is consistent with data obtained by Cave and Squire (1991), according to which performance of amnesic and control subjects was matched in spatial memory tests, indicating that the human hippocampus is not especially involved in spatial memory. They suggested instead that the hippocampus may be "necessary for rapid acquisition of relational, configural or declarative information."

\section{Working memory and visual recognition memory}

Many of the tasks used in the present study have been shown to rely on the integrity of the prefrontal cortex, yet, as shown here, they also activate the hippocampal formation. This result implicates the hippocampus in the operations of the wider working-memory system and indicates that the two structures-prefrontal cortex and hippocampus-may operate as part of the same network. Whether the preferential engagement of the direct pathway is reflective of prefrontal-hippocampal interactions remains to be determined. However, there is evidence of direct prefrontal projections within the entorhinal cortex (Goldman-Rakic et al., 1984). Finally, it may be wondered whether the match-to-sample tasks, which have been the primary behavioral instruments used to assess hippocampal function in nonhuman primates, and working-memory tasks used to assess prefrontal functions may not be related at a more fundamental processing level. DMS tasks, like delayed-response tasks, require monkeys to remember an item of information (e.g., the sample object) over a period ranging from seconds to minutes to guide selection of a novel object at the end of the delay (Mishkin, 1982). Because of the importance of delay in these tasks, it is not unreasonable to consider that the hippocampus may also be engaged in "on-line" tasks and that both structures interact when retrieval of immediate information is required just as it has been suggested that both are engaged in encoding processes (Tulving and Markowitsch, 1997; Tulving et al., 1999). Indeed, local cerebral glucose utilization is significantly elevated in the CA1, dentate gyrus, and subicular subfields of the hippocampal formation in monkeys performing spatial and object working-memory tasks (Friedman and Goldman-Rakic, 1988; Davachi et al., 1995). In addition, several studies, particularly in the rodent, have long implicated the hippocampus along with the prefrontal cortex in a role in spatial memory and spatially directed behavior (Parkinson et al., 1988; Angeli et al., 1993; Murray and Mishkin, 1998; O'Keefe, 1999; Rolls, 1999). These functional relationships between the hippocampus and prefrontal cortex are fully supported by anatomical connections between both regions (Goldman-Rakic et al., 1984; Insausti et al., 1987; Selemon and Goldman-Rakic, 1988; Suzuki and Amaral, 1994; Barbas and Blatt, 1995), which are undoubtedly the basis for their interactions. This begs the question of the unique role of each structure in on-line processing but has the appeal of integrating the medial temporal and prefrontal cortex in a common framework.

If prefrontal-hippocampal interactions are prominent during on-line retrieval operations mediated by the direct pathway, as the present findings suggest, a remaining question concerns the role of 
the trisynaptic pathway in memory functions. Buzsaki et al. (1995) have suggested that the trisynaptic pathway plays a role in error correction or novelty detection. Our results cannot speak to that issue except to support the idea of dissociable direct and indirect pathway processes.

\section{REFERENCES}

Alvarez P, Zola-Morgan S, Squire LR (1995) Damage limited to the hippocampal region produces long-lasting memory impairment in monkeys. J Neurosci 15:3796-3807.

Amaral DG, Witter MP (1989) The three-dimensional organization of the hippocampal formation: a review of anatomical data. Neuroscience 31:571-591.

Amaral DG, Dolorfo C, Alvarez-Royo P (1991) Organization of CA1 projections to the subiculum: a PHA-L analysis in the rat. Hippocampus 1:415-435.

Angeli SJ, Murray EA, Mishkin M (1993) Hippocampectomized monkeys can remember one place but not two. Neuropsychologia 31:1021-1030.

Barbas H, Blatt GJ (1995) Topographically specific hippocampal projections target functionally distinct prefrontal areas in the rhesus monkey. Hippocampus 5:511-533.

Bliss TVP, Lomo T (1973) Long-lasting potentiation of synaptic transmission in the dentate area of the anaesthetized rabbit following stimulation of the perforant path. J Physiol (Lond) 232:331-356.

Buzsaki G, Penttonen M, Bragin A, Nadasdy Z, Chrobak JJ (1995) Possible physiological role of the perforant path-CA1 projection. Hippocampus $5: 141-146$.

Cave CB, Squire LR (1991) Equivalent impairment of spatial and nonspatial memory following damage to the human hippocampus. Hippocampus 1:329-340.

Chafee MV, Goldman-Rakic PS (1998) Matching patterns of activity in primate prefrontal area 8a and parietal area 7ip neurons during a spatial working memory task. J Neurophysiol 79:2919-2940.

Davachi L, Friedman HR, Goldman-Rakic PS (1995) Increased metabolic activity in the entorhinal and perirhinal cortices and subiculum in monkeys performing working memory tasks as revealed by the 2-deoxyglucose method. Soc Neurosci Abstr 21.

Doller HJ, Weight FF (1982) Perforant pathway activation of hippocampal CA1 stratum pyramidale neurons: electrophysiological evidence for a direct pathway. Brain Res 237:1-13.

Fox SE, Ranck Jr JB (1981) Electrophysiological characteristics of hippocampal complex-spike cells and theta cells. Exp Brain Res 41:399-410.

Friedman HR, Goldman-Rakic PS (1988) Activation of the hippocampus and dentate gyrus by working-memory: a 2-deoxyglucose study of behaving rhesus monkeys. J Neurosci 8:4693-4706.

Friedman HR, Bruce CJ, Goldman-Rakic PS (1987) A sequential doublelabel 14C- and 3H-2-DG technique: validation by double-dissociation of functional states. Exp Brain Res 66:543-554.

Friedman HR, Bruce CJ, Goldman-Rakic PS (1989) Resolution of metabolic columns by a double-label 2-DG technique: interdigitation and coincidence in visual cortical areas of the same monkey. J Neurosci 9:4111-4121.

Funahashi S, Bruce CJ, Goldman-Rakic PS (1989) Mnemonic coding of visual space in the monkey's dorsolateral prefrontal cortex. J Neurophysiol 61:331-349.

Gaffan D, Murray EA (1992) Monkeys (Macaca fascicularis) with rhinal cortex ablations succeed in object discrimination learning despite 24-hr intertrial intervals and fail at matching to sample despite double sample presentations. Behav Neurosci 106:30-38.

Goldman-Rakic PS, Selemon LD, Schwartz ML (1984) Dual pathways connecting the dorsolateral prefrontal cortex with the hippocampal formation and parahippocampal cortex in the rhesus monkey. Neuroscience 12:719-743.

Insausti R, Amaral DG, Cowan WM (1987) The entorhinal cortex of the monkey. II. Cortical afferents. J Comp Neurol 264:356-395.

Jones RS (1993) Entorhinal-hippocampal connections: a speculative view of their function. Trends Neurosci 16:58-64.

Jorgensen MB, Wright DC (1988) The effect of unilateral and bilateral removal of the entorhinal cortex on the glucose utilization in various hippocampal regions in the rat. Neurosci Lett 87:227-232.

Kapur N, Brooks D (1999) Temporally-specific retrograde amnesia in two cases of discrete bilateral hippocampal pathology. Hippocampus 9:247-254.

Kartsounis LD, Rudge P, Stevens JM (1995) Bilateral lesions of CA1 and CA2 fields of the hippocampus are sufficient to cause a severe amnesic syndrome in humans. J Neurol Neurosurg Psychiatry 59:95-98.

Kennedy C, Sakurada O, Shinohara M, Jehle J, Sokoloff L (1978) Local cerebral glucose utilization in the normal conscious macaque monkey. Ann Neurol 4:293-301.

Leonard BW, Amaral DG, Squire LR, Zola-Morgan S (1995) Transient memory impairment in monkeys with bilateral lesions of the entorhinal cortex. J Neurosci 15:5637-5659.

Lomo T (1966) Frequency potentiation of excitatory synaptic activity in the dentate area of the hippocampal formation. Acta Physiol Scand 68[Suppl 277]:128.
Lopes da Silva F, Witter M, Boeijnga P, Lohman A (1990) Anatomic organization and physiology of the limbic cortex. Physiol Rev 70:453-511.

Lorente de No R (1934) Studies on the structure of the cerebral cortex. II. Continuation of the study of the ammonic system. J Psychol Neurol 46:113-177.

Malenka RC, Nicoll RA (1999) Long-term potentiation-a decade of progress? Science 285:1870-1874.

McNaughton BL, Barnes CA, O'Keefe J (1983) The contributions of position, direction, and velocity to single unit activity in the hippocampus of freely-moving rats. Exp Brain Res 52:41-49.

McNaughton BL, Barnes CA, Meltzer J, Sutherland RJ (1989) Hippocampal granule cells are necessary for normal spatial learning but not for spatially-selective pyramidal cell discharge. Exp Brain Res 76:485-496.

Meunier M, Bachevalier J, Mishkin M, Murray EA (1993) Effects on visual recognition of combined and separate ablations of the entorhinal and perirhinal cortex in rhesus monkeys. J Neurosci 13:5418-5432.

Meunier M, Hadfield W, Bachevalier J, Murray EA (1996) Effects of rhinal cortex lesions combined with hippocampectomy on visual recognition memory in rhesus monkeys. J Neurophysiol 75:1190-1205.

Mishkin M (1978) Memory in monkeys severely impaired by combined but not by separate removal of amygdala and hippocampus. Nature 273:297-298.

Mishkin M (1982) A memory system in the monkey. Philos Trans R Soc Lond B Biol Sci 298:83-95.

Miyashita Y, Rolls ET, Cahusac PM, Niki H, Feigenbaum JD (1989) Activity of hippocampal formation neurons in the monkey related to a conditional spatial response task. J Neurophysiol 61:669-678.

Murray EA, Mishkin M (1984) Severe tactual as well as visual memory deficits follow combined removal of the amygdala and hippocampus in monkeys. J Neurosci 4:2565-2580.

Murray EA, Mishkin M (1986) Visual recognition in monkeys following rhinal cortical ablations combined with either amygdalectomy or hippocampectomy. J Neurosci 6:1991-2003.

Murray EA, Mishkin M (1998) Object recognition and location memory in monkeys with excitotoxic lesions of the amygdala and hippocampus. J Neurosci 18:6568-6582.

Murray EA, Gaffan D, Mishkin M (1993) Neural substrates of visual stimulus-stimulus association in rhesus monkeys. J Neurosci 13:4549-4561.

Murray EA, Baxter MG, Gaffan D (1998) Monkeys with rhinal cortex damage or neurotoxic hippocampal lesions are impaired on spatial scene learning and object reversals. Behav Neurosci 112:1291-1303.

Newman W, Sproull R (1973) Principles of interactive computer graphics. New York: McGraw-Hill.

Nishijo H, Ono T, Eifuku S, Tamura R (1997) The relationship between monkey hippocampus place-related neural activity and action in space. Neurosci Lett 226:57-60.

O'Keefe J (1976) Place units in the hippocampus of the freely moving rat. Exp Neurol 51:78-109.

O'Keefe J (1993) Hippocampus, theta, and spatial memory. Curr Opin Neurobiol 3:917-924.

O'Keefe J (1999) Do hippocampal pyramidal cells signal non-spatial as well as spatial information? Hippocampus 9:352-364.

Olton DS, Papas BC (1979) Spatial memory and hippocampal function. Neuropsychologia 17:669-682.

Parkinson JK, Murray EA, Mishkin M (1988) A selective mnemonic role for the hippocampus in monkeys: memory for the location of objects. J Neurosci 8:4159-4167.

Ramon y Cajal S (1968) The structure of Ammon's horn. Springfield, IL.

Reed JM, Squire LR (1997) Impaired recognition memory in patients with lesions limited to the hippocampal formation. Behav Neurosci 111:667-675.

Reed JM, Squire LR (1998) Retrograde amnesia for facts and events: findings from four new cases. J Neurosci 18:3943-3954.

Rempel-Clower NL, Zola SM, Squire LR, Amaral DG (1996) Three cases of enduring memory impairment after bilateral damage limited to the hippocampal formation. J Neurosci 16:5233-5255.

Rolls E (1999) Spatial view cells and the representation of place in the primate hippocampus. Hippocampus 9:467-480.

Rolls ET, Robertson RG, Georges-Francois P (1997) Spatial view cells in the primate hippocampus. Eur J Neurosci 9:1789-1794.

Rolls ET, Treves A, Robertson RG, Georges-Francois P, Panzeri S (1998) Information about spatial view in an ensemble of primate hippocampal cells. J Neurophysiol 79:1797-1813.

Scoville W, Miller B (1957) Loss of recent memory after bilateral hippocampal lesions. J Neurol Neurosurg Psychiatry 20:11-21.

Segal M, Olds J (1972) Behavior of units in hippocampal circuit of the rat during learning. J Neurophysiol 35:680-690.

Selemon LD, Goldman-Rakic PS (1988) Common cortical and subcortical targets of the dorsolateral prefrontal and posterior parietal cortices in the rhesus monkey: evidence for a distributed neural network subserving spatially guided behavior. J Neurosci 8:4049-4068.

Sokoloff L (1993a) Function-related changes in energy metabolism in the nervous system: localization and mechanisms. Keio J Med 42:95-103.

Sokoloff L (1993b) Sites and mechanisms of function-related changes in energy metabolism in the nervous system. Dev Neurosci 15:194-206.

Sokoloff L, Reivich M, Kennedy C, Des Rosiers MH, Patlak CS, Pettigrew 
KD, Sakurada O, Shinohara M (1977) The [14C]deoxyglucose method for the measurement of local cerebral glucose utilization: theory, procedure, and normal values in the conscious and anesthetized albino rat. J Neurochem 28:897-916.

Soltesz I (1995) Brief history of cortico-hippocampal time with a special reference to the direct entorhinal input to CA1. Hippocampus 5:120-124

Soltesz I, Deschenes M (1993) Low- and high-frequency membrane potential oscillations during theta activity in CA1 and CA3 pyramidal neurons of the rat hippocampus under ketamine-xylazine anesthesia. J Neurophysiol 70:97-116.

Soltesz I, Jones RS (1995) The direct perforant path input to CA1: excitatory or inhibitory? Hippocampus 5:101-103.

Spencer W, Kandel E (1962) Hippocampal neuron responses in relation to normal and abnormal function. In: Physiologie de l'hippocampe (Passouant P, ed), pp 71-103. Paris: Centre National de la Recherche Scientifique.

Steward O (1976) Topographic organization of the projections from the entorhinal area to the hippocampal formation in the rat. J Comp Neurol 167:285-314.

Suzuki WA, Amaral DG (1994) Perirhinal and parahippocampal cortices of the macaque monkey: cortical afferents. J Comp Neurol 350:497-533.

Suzuki WA, Zola-Morgan S, Squire LR, Amaral DG (1993) Lesions of the perirhinal and parahippocampal cortices in the monkey produce long-lasting memory impairment in the visual and tactual modalities. J Neurosci 13:2430-2451.

Tulving E, Markowitsch HJ (1997) Memory beyond the hippocampus. Curr Opin Neurobiol 7:209-216.

Tulving E, Habib R, Nyberg L, Lepage M, McIntosh AR (1999) Positron emission tomography correlations in and beyond medial temporal lobes. Hippocampus 9:71-82.

Witter MP (1993) Organization of the entorhinal-hippocampal system: a review of current anatomical data. Hippocampus 3:33-44.
Witter MP, Griffioen AW, Jorritsma-Byham B, Krijnen JL (1988) Entorhinal projections to the hippocampal CA1 region in the rat: an underestimated pathway. Neurosci Lett 85:193-198.

Witter MP, Van Hoesen GW, Amaral DG (1989) Topographical organization of the entorhinal projection to the dentate gyrus of the monkey. J Neurosci 9:216-228.

Yeckel MF, Berger TW (1990) Feedforward excitation of the hippocampus by afferents from the entorhinal cortex: redefinition of the role of the trisynaptic pathway. Proc Natl Acad Sci USA 87:5832-5836.

Yeckel MF, Berger TW (1995) Monosynaptic excitation of hippocampal CA1 pyramidal cells by afferents from the entorhinal cortex. Hippocampus 5:108-114.

Zola-Morgan S, Squire LR (1986) Memory impairment in monkeys following lesions limited to the hippocampus. Behav Neurosci 100:155-160.

Zola-Morgan S, Squire LR, Amaral DG (1986) Human amnesia and the medial temporal region: enduring memory impairment following a bilateral lesion limited to field CA1 of the hippocampus. J Neurosci 6:2950-2967.

Zola-Morgan S, Squire LR, Amaral DG (1989a) Lesions of the hippocampal formation but not lesions of the fornix or the mammillary nuclei produce long-lasting memory impairment in monkeys. J Neurosci 9:898-913.

Zola-Morgan S, Squire LR, Amaral DG (1989b) Lesions of the amygdala that spare adjacent cortical regions do not impair memory or exacerbate the impairment following lesions of the hippocampal formation. J Neurosci 9:1922-1936.

Zola-Morgan S, Squire LR, Amaral DG, Suzuki WA (1989c) Lesions of perirhinal and parahippocampal cortex that spare the amygdala and hippocampal formation produce severe memory impairment. J Neurosci 9:4355-4370. 